\title{
OPTIMALISASI BIAYA TRANSPORTASI PENDISTRIBUSIAN PUPUK BERSUBSIDI MENGGUNAKAN MODEL TRANSPORTASI METODE MODIFIED DISTRIBUSITION (MODI)
}

\author{
N. Pertiwi' ${ }^{1}$ A. I. Jaya ${ }^{2}$, dan Hajar ${ }^{3}$ \\ 1,2,3 Program Studi Matematika Jurusan Matematika \\ Fakultas Matematika dan IImu Pengetahuan Alam Universitas Tadulako \\ Jalan Sukarno-Hatta Km. 9 Palu 94118, Indonesia \\ 1Nanda_angelelf@yahoo.co.id, 2jayaindraagus@gmail.com,3Hajar.200490@yahoo.com
}

\begin{abstract}
This study was conducted to obtain the optimal transport costs in the distribution of subsidized fertilizer in PT. GCS and PT.PPI. This research was done in two steps is to create a transport model of the data obtained and determine its solution initially with Least Cost method, and determine the optimal solution with ModifiedDistribution (MODI) method. Based on research that obtained the initial solution is Rp. 65.040.000 and optimal solution is Rp. 64.950.000. While the cost of transportation from the company is RP. 70.500.000. This shows that both distributors can optimize the total cost of transport for the distribution of subsidized fertilizer in January 2017 with the distribution cost savings of Rp. 5.550 .000 .
\end{abstract}

Keywords $\quad$ : Least Cost Method, Modified Method of Distribution, Optimization, Transportation

\section{ABSTRAK}

Penelitian ini dilaksanakan untuk memperoleh biaya transportasi yang optimal dalam pendistribusian pupuk bersubsidi pada PT. GCS dan PT.PPI. Penelitian ini dilakukan dengan dua langkah yaitu dengan membuat model transportasi dari data yang diperoleh kemudian menentukan solusi awalnya dengan metode Least Cost, dan menentukan solusi optimalnya dengan metode Modified Distribution (MODI). Berdasarkan hasil penelitian yang diperoleh solusi awal sebesar Rp. 65.040.000 dan solusi optimal sebesar Rp. 64.950.000. Sedangkan biaya transportasi dari perusahaan sebelum dilakukan pengoptimalan sebesar RP. 70.500.000. Hal ini menunjukan bahwa kedua distributor dapat mengoptimalkan total biaya transportasi untuk pendistribusian pupuk bersubsidi pada bulan Januari 2017 dengan penghematan biaya pendistribusian sebesar Rp. 5.550.000.

Kata Kunci : : Metode Least Cost, Metode Modified Distribution, Optimalisasi, Transportasi 


\section{PENDAHULUAN}

\subsection{Latar Belakang}

Pertanian mempunyai peranan yang sangat penting dalam pembangunan ekonomi di Indonesia. Pentingnya peranan ini menyebabkan bidang ekonomi diletakkan pada pembangunan ekonomi dengan titik berat sektor pertanian.Pembangunan pertanian diarahkan untuk meningkatkan produksi pertanian gunamemenuhi kebutuhan pangan dan kebutuhan industri dalam negeri, meningkatkan ekspor, meningkatkan pendapatan petani, memperluas kesempatan kerja dan mendorong pemerataan kesempatan berusaha (Soekarwati, 2002).

Pada bidang pertanian pupuk merupakan salah satu hal yang paling berpengaruh terhadap hasil panen, maka tidak heran pupuk menjadi faktor utama bagi para petani guna mendapatkan hasil panen yang melimpah dan berkualitas. Hal tersebut membuat pemerintah memberikan ketersediaan pupuk bersubsidi untuk para petani. Beberapa perusahaan yang menyediakan pupuk bersubsidi dan bekerjasama dengan pemerintah selalu mengharapkan keuntungan yang semaksimal mungkin agar siklus hidup perusahaan dapat tetap berjalan. Maka perusahaan tersebut harus mampu mengatur biaya antara pemasukan dan pengeluaran yang digunakan untuk pendistribusian barang berupa pupuk bersubsidi. Semakin besar rentang antara pemasukan dan pengeluaran perusahaan, maka semakin besar pula keuntungan yang akan diperoleh dengan harapan selalu lebih rendah daripada pemasukan perusahaan. Salah satu faktor yang menentukan tingkat kepuasan pelanggan adalah tepat waktunya pelayanan oleh perusahaan dalam hal pengangkutan dan pengalokasian agar sampai ke tempat tujuan.

PT. Pupuk Kaltim cabang Palu merupakan salah satu produsen yang ditunjuk langsung oleh pemerintah untuk bertugas melayani penyaluran pupuk bersubsidi yang diajukan oleh dua distributor dan disalurkan kepada sebelas pengecer yang berada di beberapa wilayah di kota palu. Dalam pendistribusian pupuk perlu meminimumkan biaya transportasi pendistribusian pupuk bersubsidi masih terbatas oleh kapasitas gudang dari tempat tujuan dan hal ini masih menjadi masalah bagi perusahaan. Pemecahan solusi ini dapat menerapkan Metode Least Cost untuk mendapatkan solusi awal dan Metode Modified Distribution (MODI).

Pada penelitian sebelumnya, telah dibahas tentang Optimasi pendistribusian pupuk di sulawesi tengah melalui model Transshipment menggunakan metode Vogel Approximation (Muhammad Safir, 2016). Untuk penelitian selanjutnya akan menggunakan metode Least Cost dan Metode MODI(Modified Distribution).

Berdasarkan latar belakang tersebut, penulis coba menuangkan masalah ini kedalam sebuah tugas akhir yang berjudul "Optimalisasi Biaya Transportasi Pendistribusian Pupuk Bersubsidi Menggunakan Model Transportasi Metode Modified Distribution (MOD). 


\subsection{Rumusan Masalah}

Rumusan masalah pada penelitian ini adalah bagaimana mengoptimalkan biaya transportasi untuk pendistribusian pupuk bersubsidi di Sulawesi Tengah dengan menggunakan model Transportasi metode Modified Distribution (MODI) pada PT GCS dan PT. PPI.

\subsection{Batasan Masalah}

Adapun asumsi yang digunakan dalam penelitian ini adalah:

1. Pada artikel ini biaya penyimpanan pada PT. Pupuk Kaltim tidak diperhitungkan.

2. Jumlah sumber yang diteliti ada 2 sumber (Distributor) dan 11 tujuan (Pengecer).

\section{METODE PENELITIAN}

a. Mulai penelitian

b. Studi literatur dengan mengumpulkan materi dari buku, artikel dan jurnal

c. Pengambilan data

d. Membuat Matriks Masalah Transportasi

e. Menentukan masalah transportasi dari berbagai sumber dan berbagi tujuan

f. Penerapan metode Least Cost pada masalah transportasi

g. Menentukan solusi optimal dari Metode Modified Distribution

h. Kesimpulan

i. Selesai

\section{HASIL DAN PEMBAHASAN}

\subsection{Hasil penelitian}

Pendistribusian Puuk Bersubsidi pada PT. Pupuk Kaltim Cabang Palu dilakukan melalui dua distributor. Adapun data persediaan, permintaan, penawaran dan biaya transportasi dari distributor ke masing-masing toko ditunjukkan pada Tabel 1.

Tabel 1: Persediaan pupuk bersubsidi di dua distributor pada bulan Januari 2017

\begin{tabular}{|c|c|l|}
\hline No. & \multicolumn{1}{|c|}{ Distributor } & Persediaan \\
\hline 1 & PT. GCS & 246 Ton \\
\hline 2 & PT. PPI & 269 Ton \\
\hline \multicolumn{2}{|c|}{ Jumlah } & 517 Ton \\
\hline
\end{tabular}

(Sumber: Dinas Pertanian Provinsi Sulawesi Tengah) 
Adapun data Kebutuhan Pupuk pada Pengecer dapat dilihat pada Tabel 2.

Tabel 2 : Kebutuhan Pupuk Pada Pengecer

\begin{tabular}{|c|c|l|}
\hline No & $\begin{array}{c}\text { Nama } \\
\text { Pengecer }\end{array}$ & $\begin{array}{l}\text { Jumlah } \\
\text { Kebutuhan }\end{array}$ \\
\hline 1 & Kios Suryani $\left(T_{1}\right)$ & 20 Ton \\
\hline 2 & Kios Herman $\left(T_{2}\right)$ & 30 Ton \\
\hline 3 & Toko Barokah $\left(T_{3}\right)$ & 32 Ton \\
\hline 4 & Kios Melati $\left(T_{4}\right)$ & 20 Ton \\
\hline 5 & KOP Bina Tani Mandiri $\left(T_{5}\right)$ & 58 Ton \\
\hline 6 & UD. Reka Jaya $\left(T_{6}\right)$ & 48 Ton \\
\hline 7 & Kios Eka( $\left.T_{7}\right)$ & 50 Ton \\
\hline 8 & Toko Sinar Tani $\left(T_{8}\right)$ & 60 Ton \\
\hline 9 & Toko Sahabat Tani $\left(T_{9}\right)$ & 69 Ton \\
\hline 10 & Kios Cendana Tani $\left(T_{10}\right)$ & 70 Ton \\
\hline 11 & UD. Mahaputra( $\left(T_{11}\right)$ & 60 Ton \\
\hline
\end{tabular}

(Sumber: Dinas Pertanian Provinsi Sulawesi Tengah)

Data penawaran keramik kesepuluh toko dari masing-masing agen dapat dilihat pada Tabel 3.

Tabel 3 : Penawaran Pupuk Ke-11 Toko Dari Distributor Pada Bulan Januari 2017

\begin{tabular}{|c|c|c|c|c|}
\hline No. & Toko & Distributor 1 $\left(S_{1}\right)$ & Distributor 2 $\left(S_{2}\right)$ & Total Permintaan \\
\hline 1 & $T_{1}$ & 12 & 8 & 20 \\
\hline 2 & $T_{2}$ & 15 & 15 & 30 \\
\hline 3 & $T_{3}$ & 17 & 15 & 32 \\
\hline 4 & $T_{4}$ & 10 & 10 & 20 \\
\hline 5 & $T_{5}$ & 28 & 30 & 58 \\
\hline 6 & $T_{6}$ & 27 & 21 & 48 \\
\hline 7 & $T_{7}$ & 25 & 25 & 50 \\
\hline 8 & $T_{8}$ & 22 & 38 & 60 \\
\hline 9 & $T_{9}$ & 36 & 33 & 69 \\
\hline 10 & $T_{10}$ & 33 & 37 & 60 \\
\hline 11 & $T_{11}$ & 32 & 28 & 70 \\
\hline
\end{tabular}

(sumber: Dinas Pertanian Provinsi Sulawesi Tengah) 
Data biaya transportasi pendistribusian pupuk bersubsidi untuk setiap pengiriman dari distributor menuju masing-masing pelanggan dapat dilihat pada Tabel 4.

Tabel 4 : Biaya Transportasi Setiap Pengiriman Pupuk bersubsidi dari distributor Menuju Masing-masing Pelanggan pada bulan Januari 2017

\begin{tabular}{|c|c|c|}
\hline \multicolumn{1}{|c|}{ Ke Dari } & Distributor 1 & Distributor 2 \\
\hline Toko 1 & Rp. 120.000 & Rp. 170.000 \\
\hline Toko 2 & Rp. 140.000 & Rp. 150.000 \\
\hline Toko 3 & Rp. 130.000 & Rp. 190.000 \\
\hline Toko 4 & Rp. 130.000 & Rp. 130.000 \\
\hline Toko 5 & Rp. 120.000 & Rp. 160.000 \\
\hline Toko 6 & Rp. 150.000 & Rp. 130.000 \\
\hline Toko 7 & Rp. 160.000 & Rp. 130.000 \\
\hline Toko 8 & Rp. 130.000 & Rp. 120.000 \\
\hline Toko 9 & Rp. 120.000 & Rp. 140.000 \\
\hline Toko 10 & Rp. 140.000 & Rp. 120.000 \\
\hline Toko 11 & Rp. 130.000 & Rp. 140.000 \\
\hline
\end{tabular}

(Sumber : PT. GCS dan PPI cabang Palu)

Dari seluruh data yang diperoleh akan dibuat matriks model transportasi dapat dilihat pada Tabel 5.

Tabel 5 : Matriks Model Transportasi

\begin{tabular}{|c|c|c|c|c|c|c|c|c|c|c|c|c|}
\hline Dark & $T_{1}$ & $T_{2}$ & $T_{3}$ & $T_{4}$ & $T_{5}$ & $T_{6}$ & $T_{7}$ & $T_{8}$ & $T_{9}$ & $T_{10}$ & $T_{11}$ & $\begin{array}{l}\text { Penawar } \\
\text { an } \\
\quad\left(S_{i}\right)\end{array}$ \\
\hline \multirow{2}{*}{$\left(S_{1}\right)$} & 120 & 140 & 130 & 130 & 120 & 150 & 160 & 130 & 120 & 140 & 130 & \multirow{2}{*}{248} \\
\hline & $X_{11}$ & $X_{12}$ & $X_{13}$ & $X_{14}$ & $X_{15}$ & $X_{16}$ & $X_{17}$ & $X_{18}$ & $X_{19}$ & $X_{110}$ & $X_{1,11}$ & \\
\hline \multirow{2}{*}{$\left(S_{2}\right)$} & 170 & 150 & 190 & 130 & 160 & 130 & 130 & 120 & 140 & 120 & 140 & \multirow{2}{*}{269} \\
\hline & $X_{21}$ & $X_{22}$ & $X_{23}$ & $X_{24}$ & $X_{25}$ & $X_{26}$ & $X_{27}$ & $X_{28}$ & $X_{29}$ & $X_{2.10}$ & $X_{2,11}$ & \\
\hline $\begin{array}{l}\text { Permint } \\
\text { aan } \\
\left(P_{j}\right)\end{array}$ & 20 & 30 & 32 & 20 & 58 & 48 & 50 & 60 & 69 & 70 & 60 & $\begin{array}{l}517 \\
517\end{array}$ \\
\hline
\end{tabular}


Dari Tabel 5, akan diformulasiakan model program liniernya sebagai berikut :

\section{Meminimumkan}

$$
\begin{aligned}
& F=\sum_{i=1}^{m} \sum_{j=1}^{n} c_{i j} \cdot x_{i j} \\
& F=120000 X_{11}+140000 X_{12}+130000 X_{13}+130000 X_{14}+120000 X_{15}+150000 X_{16}+ \\
& 160000 X_{17}+130000 X_{18}+120000 X_{19}+140000 X_{1.10} 130000 X_{1.11}+170000 X_{21}+ \\
& 150000 X_{22}+190000 X_{23}+130000 X_{24}+160000 X_{25}+13000 X_{26}+130000 X_{27}+ \\
& 120000 X_{28}+140000 X_{29}+120000 X_{2.10}+140000 X_{2.11}
\end{aligned}
$$

\section{Dengan batasan :}

$\sum_{i=1}^{m} x_{i j}=S_{i}$

$X_{11}+X_{12}+X_{13}+X_{14}+X_{15}+X_{16}+X_{17}+X_{18}+X_{19}+X_{1.10}+X_{1.11} \leq 248$

$X_{21}+X_{22}+X_{23}+X_{24}+X_{25}+X_{26}+X_{27}+X_{28}+X_{29}+X_{2.10}+X_{2.11} \leq 269$

$\sum_{j=1}^{n} x_{i j}=P_{i}$

$X_{11}+X_{12} \leq 20$

$X_{12}+X_{22} \leq 30$

$X_{13}+X_{23} \leq 32$

$X_{14}+X_{24} \leq 20$

$X_{15}+X_{25} \leq 58$

$X_{16}+X_{26} \leq 48$

$X_{17}+X_{27} \leq 50$

$X_{18}+X_{28} \leq 60$

$X_{19}+X_{29} \leq 69$

$X_{1.10}+X_{2.10} \leq 70$

$X_{1.11}+X_{2.11} \leq 60$

Selanjutnya dari data yang telah diperoleh akan dicari solusi awalnya dengan menggunakan metode ongkos terkecil (Least Cost).

Tabel 6 : Tabel Solusi Awal Masalah Transportasi

\begin{tabular}{|c|c|c|c|c|c|c|c|c|c|c|c|c|}
\hline Ke & $T_{1}$ & $T_{2}$ & $T_{3}$ & $T_{4}$ & $T_{5}$ & $T_{6}$ & $T_{7}$ & $T_{8}$ & $T_{9}$ & $T_{10}$ & $T_{11}$ & $\begin{array}{l}\text { Penawar } \\
\text { an } \\
\left(S_{i}\right)\end{array}$ \\
\hline$\left(S_{1}\right)$ & & & & & & & & & & & & \\
\hline
\end{tabular}


Dari Tabel 6 dapat diketahui biaya total transportasi pendistribusian pupuk bersubsidi sebagai berikut :

$$
\begin{aligned}
F= & 20\left(X_{11}\right)+32\left(X_{13}\right)+9\left(X_{14}\right)+58\left(X_{15}\right)+69\left(X_{19}\right)+60\left(X_{1,11}\right)+30\left(X_{22}\right)+11\left(X_{24}\right)+ \\
& 48\left(X_{26}\right)+50\left(X_{27}\right)+60\left(X_{28}\right)+70\left(X_{2,10}\right) \\
= & 20(120000)+32(130000)+9(130000)+58(120000)+69(120000)+60(130000)+ \\
& 30(150000)+11(130000)+48(130000)+50(130000)+60(120000)+70(120000) \\
= & 65.040 .000
\end{aligned}
$$

Dari hasil diatas dapat disimpulkan solusi awal biaya transportasi pendistribusian pupuk bersubsidi menggunakan metode Least Cost sebesar Rp. 65.040 .000 perbulan. Untuk memperoleh biaya transportasi yang optimal (biaya murah) pendstribusian pupuk bersubsidi,

\begin{tabular}{|c|c|c|c|c|c|c|c|c|c|c|c|c|c|}
\hline $\begin{array}{l}K_{j} \\
R_{j}\end{array}$ & & $\begin{array}{c}K_{1} \\
120\end{array}$ & $\begin{array}{c}K_{2} \\
140\end{array}$ & $\begin{array}{c}K_{3} \\
130\end{array}$ & $\begin{array}{c}K_{4} \\
130\end{array}$ & $\begin{array}{c}K_{5} \\
120\end{array}$ & $\begin{array}{c}K_{6} \\
130\end{array}$ & $\begin{array}{c}K_{7} \\
130\end{array}$ & $\begin{array}{c}K_{8} \\
130\end{array}$ & $\begin{array}{c}K_{9} \\
120\end{array}$ & $\begin{array}{l}K_{10} \\
120\end{array}$ & $\begin{array}{l}K_{11} \\
130\end{array}$ & \\
\hline & $\mathrm{Ke}$ & $T_{1}$ & $T_{2}$ & $T_{3}$ & $T_{4}$ & $T_{5}$ & $T_{6}$ & $T_{7}$ & $T_{8}$ & $T_{9}$ & $T_{10}$ & $T_{11}$ & Penawaran \\
\hline & & & & & & 120 & 150 & & & & & & \\
\hline \multirow{3}{*}{$\begin{array}{l}R_{1} \\
0\end{array}$} & \multirow{3}{*}{$\left(S_{1}\right)$} & 120 & 140 & 130 & 130 & \multirow{2}{*}{\multicolumn{2}{|c|}{58}} & 160 & 130 & 120 & 140 & 130 & \multirow{3}{*}{248} \\
\hline & & & & & & & & & & & & & \\
\hline & & 20 & 9 & 32 & & 160 & 130 & & & 69 & & 60 & \\
\hline \multirow[t]{2}{*}{$R_{2}$} & \multirow{2}{*}{$\left(S_{2}\right)$} & 170 & 150 & 190 & 130 & & & 130 & 120 & 140 & 120 & 140 & \multirow{2}{*}{269} \\
\hline & & & 21 & & 20 & & & 50 & 60 & & 70 & & \\
\hline & $\begin{array}{l}\text { Permintaan } \\
\qquad\left(P_{j}\right)\end{array}$ & 20 & 30 & 32 & 20 & 58 & 48 & 50 & 60 & 69 & 70 & 60 & 517 \\
\hline
\end{tabular}
langkah selanjutnya akan dikerjakan dengan metode MODI. Setelah dilakukan langkahlangkah dalam menentukan solusi optimal didapatkan biaya transportasi optimal yang di tunjukkan pada Tabel 7.

Tabel 7 : Biaya Transportasi yang Optimal

Biaya transportasi $=20(120000)+9(140000)+32(130000)+58(120000)+69(120000)+$

$$
\begin{aligned}
& \quad 60(130000)+21(150000)+20(130000)+48(130000)+ \\
& 50(130000)+60(120000)+70(120000) \\
& =64.950 .00
\end{aligned}
$$

\subsection{Pembahasan}

Pendistribusian pupuk bersubsidi pada Gudang PT. Pupuk Kaltim yang ditunjuk langsung oleh pemerintah melalui dua distributor yaitu PT. GCS sejumlah 248 dan PT. PPI sejumlah 269, masing-masing distributor tersebut harus mendistribusikan pupuk bersubsidi kepada sebelas Toko yang merupakan pelanggan dari kedua distributor dengan jumlah permintaan dari masing-masing Toko pada bulan Januari 2017 yaitu $T_{1}=20, T_{2}=30, T_{3}=32$, $T_{4}=20, T_{5}=58, T_{6}=48, T_{7}=50, T_{8}=60, T_{9}=69, T_{10}=70, T_{11}=60$ dengan biaya 
transportasi yang berbeda-beda disesuaikan dengan jarak setiap kali pengiriman dan total biaya transportasi untuk pendistribusian pupuk dari kedua distributor menuju kesebelas toko sebesar RP. 70.500 .000 perbulan. Untuk mendapatkan biaya transportasi pendistribusian pupuk bersubsidi yang optimal dilakukan perhitungan menggunakan model transportasi metode MODI, karena indeks perbaikan tidak ada yang bernilai negatif tabel transportasi tidak memungkinkan untuk dimodifikasikan lagi.

Pada Tabel 4 merupakan tabel pemecahan optimal pendistribusian pupuk kesebelas toko tujuan, yaitu Toko Barokah $\left(T_{1}\right)$, Kios Herman $\left(T_{2}\right)$, Kios Suryani $\left(T_{3}\right)$, Kios Melati $\left(T_{4}\right), \operatorname{KOP}$ Bina Tani Mandiri $\left(T_{5}\right)$, UD. Reka Jaya $\left(T_{6}\right)$, Kios Eka( $\left(T_{7}\right)$, Toko Sinar Tani $\left(T_{8}\right)$, Toko Sahabat Tani $\left(T_{9}\right)$, Kios Cendana Tani $\left(T_{10}\right)$, UD. Mahaputra $\left(T_{11}\right)$ dimana jumlah permintaan dan penawaran telah dipenuhi sebanyak 517 Ton. Distributor 1 mendistribusikan pupuk bersubsidi ke enam toko tujuan yaitu $\left(T_{1}, T_{2}, T_{3}, T_{5}, T_{9}, T_{11}\right)$ dan distributor 2 juga mendistribusikan pupuk bersubsidi ke enam toko tujuan yaitu $\left(T_{2}, T_{4}, T_{6}, T_{7}, T_{8}, T_{10}\right)$ dengan total biaya transportasi Rp. 64.950.000 perbulan.

Pada Tabel 5 dapat disimpulkan bahwa terdapat perbedaan dalam biaya transportasi pendistribusian pupuk oleh distributor. Distribusi sebelum menggunakan metode transportasi yang ditinjaukan Tabel 5 sebesar Rp. 70.500 .000 perbulan, sementara metode transportasi menghasilkan pula distribusi oleh setiap distributor ke beberapa toko dengan biaya operasional mencapai Rp.64.950.000. Hal ini menunjukan bahwa metode transportasi mampu memberikan solusi biaya yang minimum dalam upaya mendapatkan biaya distribusi, dimana pada kasus ini mampu menghemat biaya hingga Rp.5.550.000 perbulan.

\section{KESIMPULAN}

Berdasarkan hasil dan pembahasan yang telah dilakukan, dapat disimpulkan bahwa biaya transportasi pendistribusian pupuk bersubsidi pada bulan Januari 2017 dengan model Transportasi, untuk solusi awal menggunakan metode Least Cost yaitu sebesar $R p .65 .040 .000$ dan untuk solusi optimal menggunakan metode Modified Distribution (MODI) di peroleh biaya transportasi optimal yaitu sebesar $R p .64 .950 .000$ perbulan. Sedangkan biaya transportasi sebelum pengoptimalan dari perusahaan yaitu sebesar $R p .70 .500 .000$ perbulan. Hal ini menunjukan bahwa dua distributor dapat mengoptimalkan biaya transportasi untuk pendistribusian produk pupuk pada bulan Januari 2017 , dengan penghematan biaya pendistribusian sebesar $R p .5 .550 .000$ per bulan. 


\section{DAFTAR PUSTAKA}

[1] Aminudin, Prinsip-Prinsip Riset Operasi, 2005, Erlangga, Jakarta.

[2] Nirwansyah, Widowati, (Seminar Nasional aplikasi sains dan Matematika Dalam Industri) Efesiensi Distribusi Biaya Dengan Metode Transportasi, Jurusan Matematika FMIPA UNDIP, 2007, Semarang.

[3] Prawirosentono, S, Riset Operasi dan Ekonofisika, 2005, Bumi Askara Jakarta.

[4] Safir, Muhammad, Optimasi Pendistribusian Pupuk Di Sulawesi Tengah Melalui Model Transshipment Menggunakan Metode Vogel Approximation, 2016, FMIPA Universitas Tadulako.

[5] Sitinjak, dan Tumpal, J. R, (Riset Operasi Untuk Pengambilan Keputusan Manajerial Dengan Aplikasi Excel, 2006, Graha IImu, Yogyakarta.

[6] Soekarwati, IImu Usaha Tani dan Penelitian Untuk Pengembangan Petani Kecil, 2002, UI Press, Jakarta.

[7] Supranto, J, Linier Prograning, 1980, Fakultas Ekonomi Universitas Indonesia, Jakarta.

[8] Sutapa, N, Desain Rute Dan Penjadwalan Kendaraan Distribusi Air Mineral Wilayah Surabaya (Zeplin@Peter.Pertra.Ac.Ad, Matapa@Peter.Petra.Ac.Id), 2007, diakses 23 agustus 2016.

[9] Taha, H. A, Riset Operasi, 1996, Birorupa Aksara, Jakarta Barat. 